\title{
Transfer of Ethylene from Natural Gas during Aseptic Technique: A Possible Source of Error in Acetylene Reduction Experiments
}

\author{
By KEITH JONES \\ Department of Biological Sciences, University of Lancaster, Lancaster LA1 $4 Y Q$
}

(Received 8 March 1978)

INTRODUCTION

A project student in our laboratory obtained inexplicable results whilst using the acetylene reduction method (Stewart et al., 1967; Hardy et al., 1968). All her data showed consistently high values for ethylene when a range of values had been expected. It was noted that during this experiment, which required transfer of cultures using aseptic procedures, she was using a blue, but partially vented, Bunsen flame. When the experiment was repeated using a fully vented Bunsen flame during aseptic transfer, the predicted range of data was obtained. This led to an investigation into the transfer of ethylene during aseptic procedures and the implications for acetylene reduction assays.

\section{METHODS}

The tops were removed from Bijou bottles $\left(7 \mathrm{~cm}^{3}\right.$, with tops drilled to expose rubber liners to facilitate transfer of gas with a syringe) and the necks of the bottles were heated in a Bunsen flame using a standard aseptic procedure. The tops were immediately replaced. During exposure to the flame the bottles were held at $45^{\circ}$ to avoid spillage of contents and to prevent abnormal amounts of gas entering the bottles.

Ethylene was measured by injecting $1 \mathrm{~cm}^{3}$ of the atmosphere from the bottle into a Varian Aerograph Series 1400 gas chromatograph. The column $(2.7 \mathrm{~m} \times 2.5 \mathrm{~mm}$ diam.) was packed with Poropak $R$ and run at $50{ }^{\circ} \mathrm{C}$ with nitrogen as the carrier gas at $30 \mathrm{~cm}^{3} \mathrm{~min}^{-1}$. The presence of ethylene derived from the Bunsen flame was confirmed by comparing its retention time on the column of the gas chromatograph with that for pure ethylene and by enhancement of its peak with the pure gas.

\section{RESULTS}

Aseptic procedures were carried out with Bijou bottles containing $1 \mathrm{~cm}^{3}$ sterile medium. Different Bunsen flames were used ranging from yellow, with the air vent closed, to blue, with the air vent fully open. The results (Table 1) show that ethylene is transferred during aseptic technique if the air vent is less than $50 \%$ open and that the longer the time the neck of the vessel is in the flame the more ethylene is transferred. The time taken for standard aseptic technique will vary with the operator but the author takes between 1.5 and $2 \mathrm{~s}$.

\section{DISCUSSION}

Workers using aseptic techniques involving the use of Bunsen-burners burning natural gas and who do not wish to expose cultures to large doses of ethylene should use fully vented Bunsen flames since quiet, blue flames contain ethylene. The effects of ethylene on plant growth are well known (Abeles, 1973), but the transfer of ethylene during aseptic procedures may not be fully recognized and the implications for work with micro-organisms and tissue cultures sensitive to ethylene are obvious. 
Table 1. Effects of flaming time on the transfer of ethylene to Bijou bottles during aseptic procedure using a range of Bunsen flames

$\begin{array}{lcccc}\begin{array}{c}\text { Bunsen flame } \\ \text { (colour) }\end{array} & \begin{array}{c}\text { Air vent } \\ \text { (\% open) }\end{array} & \begin{array}{c}\text { Time in flame } \\ (\mathrm{s})\end{array} & \overbrace{(\mu \mathrm{g} / \text { bottle })} & \text { (p.p.m.) } \\ \text { Unlit } & \text { Closed } & 1-2 & 0 & 0 \\ \text { Yellow } & \text { Closed } & 1-2 & 3 \cdot 78 & 630 \\ \text { Blue } & 10 & 1-2 & 1 \cdot 38 & 230 \\ \text { Blue } & 10 & 5 & 3 \cdot 06 & 510 \\ \text { Blue } & 25 & 1-2 & 0 \cdot 92 & 152 \\ \text { Blue } & 25 & 5 & 1.98 & 330 \\ \text { Blue } & 50 & 1-2 & 0 & 0 \\ \text { Blue } & 50 & 5 & 0 \cdot 35 & 59 \\ \text { Blue } & 75 & 1-2 & 0 & 0 \\ \text { Blue } & 75 & 5 & \text { Trace } & \text { Trace } \\ \text { Blue } & 100 & 1-2 & 0 & 0 \\ \text { Blue } & 100 & 5 & 0 & 0\end{array}$

There are occasions when the transfer of ethylene from Bunsen flames can interfere with acetylene reduction experiments. In long-term growth experiments, when samples of a culture are regularly taken and tested for acetylene reduction, the culture must be maintained free of contaminating bacteria from the atmosphere. Therefore, although the exposure time to acetylene may be short and not require the use of aseptic procedures, such techniques are frequently employed because they are being used for transferring material from the growing culture. Thus the culture is repeatedly dosed with ethylene and the bottle used for the acetylene assay has ethylene trapped in it. In the experiment quoted in the Introduction the student used a partially vented blue flame and inadvertently added $19 \cdot 8 \mu \mathrm{g}$ ethylene to each of the vessels to be used for acetylene reduction assays. This masked the ethylene formed as a result of acetylene reduction.

Ethylene transferred during aseptic procedures is only a major problem if the containers are immediately sealed. Normally cultures are grown aerobically or anaerobically in which case any ethylene is lost due to diffusion into the atmosphere from aerobic cultures or flushed out during the provision of anaerobic conditions for anaerobic cultures.

The amounts of ethylene transferred differed from day to day. Such variations were attributed to differences in the composition of natural gas.

Where aseptic techniques are used during acetylene reduction experiments, appropriate controls should be carried out which take into account both the time taken and the number of aseptic transfers used.

The author wishes to thank Miss Cheryl Bean for obtaining the strange results which led to an appreciation of the problem.

\section{REFERENCES}

Abeles, F. B. (1973). Ethylene in Plant Biology. New York and London: Academic Press.

Hardy, R. F. W., Holsten, R. D., Jackson, E. K. \& Burns, R. C. (1968). The acetylene-ethylene assay for $\mathrm{N}_{2}$ fixation: laboratory and field evaluation. Plant Physiology, Lancaster 43, 1185-2207.
Stewart, W. D. P., Fitzgerald, G. P. \& Burris, R. H. (1967). In situ studies on $\mathrm{N}_{2}$ fixation using the acetylene reduction technique. Proceedings of the National Academy of Sciences of the United States of America 58, 2071-2078. 